\title{
Characteristics of senior centre users - and the impact of a group programme on social support and late-life depression
}

\author{
Hege Bøen \\ Diakonhjemmet Høgskole, Postboks 184 Vinderen, 0319 Oslo \\ E-post: boen@diakonhjemmet.no Telefon: $22963727 / 47010609$
}

\begin{abstract}
Background: Senior centres are described as arenas for prevention. However, few studies have addressed this subject. The main aims of the present study were to evaluate the impact of a senior centre programme on depression and social support, to gain knowledge about the socio-demographic, psychosocial and health characteristics of users of the senior centres in relation to non-users, and to investigate the associations between psychological distress and social support and somatic and socio-demographic factors.

Methods: Data were obtained from the Norwegian Population Register for two municipal districts in Oslo. A random sample was drawn limited to 4,000 of the total number of residents over 65 years living at home. Self-report questionnaires were sent by post. The response rate was $64 \%$ and $n=2,387$. Psychological distress was assessed using Hopkins Symptom Checklist (HSCL-10) and social support with Oslo-3 Social Support Scale. Beck Depression Inventory (BDI) was an outcome measure in addition to scales of health and life satisfaction. In total 415 persons fulfilled the inclusion criteria of the RCT and 92 completed the study.

Findings: High age and specific health problems were associated with increased use of the senior centre. Single women used the senior centres more than married women whereas single men used the senior centres less than married men. Lack of social support and somatic health problems increased psychological distress. Physical impairments and hearing in particular was associated with low levels of social support which again was associated with psychological distress. There were no significant effects on depression of the group programme. However, based on data from one year follow-up, the programme may have a delayed effect due to a general age-dependent increase in depression. This means that the intervention does not make any significant difference to persons with an already manifest depression, but likely prevents worsening for those with milder symptoms. Social support and quality of life were moderately improved.

Conclusion: The findings document a public health problem since the prevalence of physical impairments is high and loneliness is quite common and might lead to increased psychological distress. A further evaluation of these programmes is necessary to capture the effectiveness of the specific parts of the programme's content.
\end{abstract}

\section{INTRODUCTION}

The senior centre is the only service provision in Norwegian senior care serving both fit and less well functioning pensioners. Senior centers have the goals of maintaining physical and psychological activity, functional health, protection and promotion of selfsufficiency and prevention of psychosocial problems of loneliness and isolation in the elderly (2). They are organized as small local units for activity and social contact. Senior centers have a small staff of 2-4 persons and are run for a large part by volunteers. They can be characterized as a welfare service and a private responsibility, not a statutory care service such as home help, home nursing and residential care facilities. Leading researchers of the elderly charting the course of the senior centre indicate their significant potential in the preventive arena $(3,4)$. Previous results of research on and reports from senior centres in Norway show that the percentage of users is close to $50 \%$ and there is a potential for more users (5).

Depression and depressive symptoms are the most prevalent mood disorders among elders (6). Late-life depression is often related to somatic health problems resulting from chronic diseases or other impairments
(7). The combination of chronic diseases and depressive conditions causes dramatic reductions in quality of life $(8,9)$.

Epidemiological studies conducted from 1999-2006 suggest that as much as $15-16 \%$ of community dwelling elders suffer from clinically significant depressive conditions (10). A Norwegian study reported that the prevalence of depression increased with age and was highest among the oldest, $20 \%$ of those 80 years and more reported depression (11). A report from the Norwegian Institute of Public Health shows that the oldest have higher prevalence of psychological distress than those who belong to the youngest among elderly persons, 65-70 years (12). The impact of social support on mental and physical health is well documented $(8,13)$. Social isolation and loneliness are among the most potent predictors of depressive symptoms among elders (14). A recent study shows that loneliness in older persons is a predictor of both functional decline and death (15). Lack of social support increases the risk of mental disorders and is linked to all-cause mortality, cardiovascular disease, stroke and infectious diseases (16). Lack of social support increases exposition for negative life strain and reduces coping abilities in dealing with the strain. Reduced coping abilities impact 
mental health by reducing self-efficacy and selfesteem and somatic health through developing stress reactions (17).

The aim of the present research, conducted by the Norwegian Institute of Public Health, Division of Mental Health, was to evaluate the senior centre programme described below. This paper is based on information presented in the present author's PhD thesis (1).

The National association for public health is a nonprofit organization that owns and runs about 30 senior centres in Norway. In 2006 it designed and initiated the group programme "Senior centre - a service to elders with failing health". Its aims were to reach out to elderly people with symptoms of loneliness and some symptoms of psychological distress and also to increase the use of senior centres in a selection of elderly people in two districts of Oslo, Norway. By having these people participate in common senior centre activities, we hypothesised that outcomes could be increased by social support, alleviating and preventing depression and increased self-rated health and satisfaction with life.

Different studies point to the impact of both physical health and social support on the mental health of older persons (18-20). The clustering of somatic health problems, including a lack of social support, loneliness, isolation and depression seems to define a group of older persons with poor quality of life $(9,13,21)$ and the recognition and prevention of later-life depression that helps to address these factors is an important public health issue (22). The associations between the factors, however, are complex, and it is difficult to single out what is cause and effect, thereby making prevention difficult.

Studies looking into socio-demographic, psychosocial and health characteristics of Norwegian senior centre users are old with relatively small samples and conflicting conclusions $(4,23)$. We were not able to detect any controlled studies of the effect of senior centres' programme on persons' mental health, wellbeing and social support, nationally or internationally.

The present paper will specifically focus on senior centre users and their somatic health, psychological health, and socio-demographic conditions compared to the non-users. An additional aim is to investigate potential associations between psychological distress and social support, and between psychological distress and somatic and socio-demographic factors. A third aim is to examine the effect of the preventive senior centre group programme on depression, social support, selfrated health and satisfaction with life.

\section{THE INTERVENTION}

The intervention programme consisted of a weekly meeting of 3 hours duration, carried out 35 to 38 times during a year at three different senior centres. The 5 groups had a fixed membership and counted 7-10 participants each. The offer embodied transport to and from the senior centre if needed and warm meals at a low cost. A physical training programme developed by physiotherapists especially for older persons was included. It was easy to practice with a chair without changing clothes, footwear etc. The groups discussed topics the participants agreed upon themselves, such as safety in the home and outdoors, how to avoid falling, social relations and aging, humour and laughter. These elements of the programme were well-known as key elements in daily activities at the centres. They were put together on the basis that if the participants who were slightly depressed when recruited would attend these groups. The content was well-known for the participants, and not too lengthy. The group leaders were volunteers who had completed a training course for group leaders and they were supervised by the project leader, who was a registered nurse and an experienced senior centre leader.

The control group was free to continue daily activities as they chose, and they were offered the same group activities as the intervention group after one year (delayed intervention). The program started in late January 2007 approximately six weeks after baseline interviews. Follow up interviews took place in November/December the same year. The researchers had no part in planning or organizing this intervention.

\section{MATERIAL AND METHODS}

The study was approved by the Data Inspectorate and the National Committee for Medical and Health Research Ethics, (Southeast Region) in 2006.

\section{Sample design and data collection}

The present paper is based on two cross-sectional studies and a randomized controlled trial, RCT. The sampling frame for data used in the two cross-sectional studies, were obtained from the Norwegian Population Register for two municipal districts in Oslo, one western (Ullern) and one eastern (Østensjø). The median age was 76 years in Østensjø and 77 years in Ullern.

A random sample of 4,000 persons aged 65 years or more living at home, with 2,000 from each district was drawn. Self-report questionnaires and a letter of invitation with general information were sent by post. The response rate was $64 \%$. Study population stratified by gender and age within municipal districts, $n=2,387$ are presented in Table 1 . The study population is contrasted with the total number of citizens over 65 years of age in the two municipal districts.

\section{Variables}

Psychological distress

The indicator of psychological distress, was measured using the Hopkins Symptom Checklist (10 questions HSCL-10), which is the short form of a battery of 25 questions (HSCL-25) measuring the symptoms of anxiety and depression (24). A score of 1.85 or higher indicates symptoms of anxiety and depression that 
Table 1. Study population stratified by gender and age within city districts $(n=2,387)$.

\begin{tabular}{|c|c|c|c|c|c|c|c|}
\hline & \multirow[b]{2}{*}{ Age } & \multicolumn{2}{|c|}{$\begin{array}{c}\text { Total number* } \\
\mathrm{n}=17,525\end{array}$} & \multicolumn{2}{|c|}{$\begin{array}{c}\text { Invitees } \\
\mathrm{n}=3,889\end{array}$} & \multicolumn{2}{|c|}{$\begin{array}{c}\text { Respondents } \\
n=2,387\end{array}$} \\
\hline & & $\mathrm{n}$ & $(\%)$ & $\mathrm{n}$ & $(\%)$ & $\mathrm{n}$ & $(\%)$ \\
\hline \multicolumn{8}{|l|}{ Ullern } \\
\hline \multirow[t]{3}{*}{ Men } & $65-69$ & 889 & (24) & 237 & (31) & 112 & (22) \\
\hline & $70-79$ & 1,673 & (45) & 302 & (39) & 226 & (44) \\
\hline & $80+$ & 1,138 & (31) & 229 & (30) & 177 & (34) \\
\hline \multirow[t]{3}{*}{ Women } & $65-69$ & 1,018 & (18) & 258 & (22) & 142 & (20) \\
\hline & $70-79$ & 2,393 & (42) & 436 & (38) & 310 & (43) \\
\hline & $80+$ & 2,320 & (40) & 466 & (40) & 267 & (37) \\
\hline \multicolumn{8}{|l|}{ Ostensjo } \\
\hline \multirow[t]{3}{*}{ Men } & $65-69$ & 536 & (18) & 536 & (22) & 75 & (17) \\
\hline & $70-79$ & 1,555 & $(52)$ & 1,555 & (48) & 233 & (53) \\
\hline & $80+$ & 911 & (30) & 911 & (30) & 135 & (30) \\
\hline \multirow[t]{3}{*}{ Women } & $65-69$ & 823 & (16) & 233 & (19) & 125 & (18) \\
\hline & $70-79$ & 2,457 & (48) & 580 & (47) & 354 & (50) \\
\hline & $80+$ & 1,812 & (36) & 425 & (34) & 231 & (32) \\
\hline \multicolumn{8}{|l|}{ Total } \\
\hline Men & & 6,702 & (38) & 1,491 & $(38)$ & 958 & $(40)$ \\
\hline Women & & 10,823 & (62) & 2,398 & (62) & 1,429 & (60) \\
\hline
\end{tabular}

interfere with daily living, but do not necessarily require treatment (25). The HSCL-10 is recommended for screening purposes because this scale represents the best compromise between economy and accuracy in identifying "distressed" and "non-distressed" groups in the general population (26).

\section{Social support}

Social support was measured using the Oslo-3 Social Support Scale (OSS-3) with three questions (27). The response categories were assessed independently for each of the three questions, and a sum score was created by summarizing the raw scores. The Oslo- 3 scale has been used in several studies, thus confirming its feasibility and predictive validity with respect to psychological distress (27-30). In this study, the scale is used as both a sum score and an item-by-item scale. To state the prevalence of social support, we used the sum score scale ranging from 3-14, which was then operationalized into three broad categories: "poor support" 3-8, "moderate support" 9-11 and "strong support" 12-14. To test the correlations between physical impairments and diagnoses, the scale was used both item-by-item and by sum score. In a logistic regression we used the scale item-by-item to explore the contribution and changes of the three items (Oslo $1,2,3)$ when adjusted for all variables.

- Oslo 1: How many people are you so close to that you can count on them if you have great personal problems? (none (1), 1-2 (2), 3-5 (3), 5+ (4))

- Oslo 2: How much interest and concern do people show in what you do? (a lot (5), some (4), uncertain (3), little (2), none (1))

- Oslo 3: How easy is it to get practical help from neighbours if you should need it? (very easy (5), easy (4), possible (3), difficult (2), very difficult (1))
The way that social support and psychological distress are defined in the present study raises the question of whether we are dealing with distinct constructs other than psychological distress. To explore the underlying structure and proximality of the HSCL-10 and OSS-3 scales, a principal component analysis (PCA) has been carried out including, all the items of social support and psychological distress. A correlation analysis exhibits moderate correlations between psychological distress and the three social support items (HSCL-10 and (1) number of friends to count on, $-.264 * *$, (2) concern from others, $-.271^{* *},(3)$ practical help, $\left.-.182 * *\right)$, which indicates that we are dealing with different constructs. This is confirmed in the principal component analysis, in which the items of psychological distress and social support are clearly loading on two different components. Of the total variance, $39 \%$ is explained by component 1 and $15 \%$ by component 2 .

\section{Somatic health problems}

Somatic health problems were measured by questions about the presence of eight frequently occurring diagnoses: diabetes, chronic lung disease, osteoporosis, musculoskeletal ailments, coronary infarct, angina, stroke and cancer (31). The scoring alternatives were 'yes' or 'no'. The question to be answered was: "Do you have or have you had some of the listed diagnoses?" The physical impairments covered were those of balance, hearing, vision, continence and memory, all of which are also common in older years (scoring alternatives: 'yes' or 'no').

\section{Socio-economic status}

Socio-economic status was measured by educational level and income, with the educational level ranging from nine years of primary school, 12 years of secondary school and more than 12 years of college/univer- 
sity. The income was given in thousands (Norwegian kroner (NOK)), including 150', 150-200', 200-300', 300 ' or more.

In the third study with randomized controlled design the recruitment of participants was from the same data material as described above. Trial registration number is: DRKS: 00003120 on DRKS. In total 415 persons fulfilled the inclusion criteria, 277 persons dropped out. For recruitment to the trial, an initial inclusion criterion was 'having psychological distress according to Hopkins Symptom Checklist-10 (HSCL10 ) in the range of 1.39 to 1.99 ', which corresponds to 'light depression'. Two other criteria were that the subjects should not have been regular users of the senior centre already, and that they wanted to be part of the current study. Of the 2,387 persons who responded satisfactorily to questionnaire a total of 138 persons were randomized into an intervention group $(\mathrm{N}=77)$ and a control group $(\mathrm{N}=61)$. Final analyses included 92 persons. Social support (OSS-3), life satisfaction and health were measured in interviews at baseline and after 12 months (at the end of the intervention programme). Another outcome parameter was depression, as measured on the Beck Depression Inventory (BDI). The BDI is a 21-item, self-report scale, ranging from 0 (normal) to 3 (most severe), with a total maximum depression score of 63 . This questionnaire is psychometrically tested and widely used among older adults, though not specifically developed for the geriatric population (32-35).

After 12 months, the intervention group was also asked how much the weekly group programme meant to them, ranging from very much to too little. They were also asked if they had made any new friends or met the other participants in a private setting.

\section{Statistical analyses}

The level of significance was set to $p \leq 0.05$ and $95 \%$ confidence intervals were calculated in all three studies. Versions 15 and 17 of SPSS (Statistical Package for the Social Sciences) were used in the data analyses.

Correlations between variables were explored using Pearson's r. Chi-square-tests examined the gender differences. A principal component analysis (PCA) included all items of social support and psychological distress. Partial correlations were used, while associations were studied by logistic regression as well as odds ratios (ORs) between independent variables with psychological distress (dependent variable). Mean scores, SD, SE and CI were used to describe the changes in outcomes in the trial. Effect sizes were calculated based on the original scales and as Cohen's d. Paired sample tests and ANOVA were used to test group differences.

\section{RESUltS}

In the first cross-sectional study we aimed at describing the socio-demographic, psychosocial and health characteristics of users and non-users of the senior centre. The percentage of users among the survey respondents was 44 and women used the centres more than men. Age and specific health problems were the most significant variables explaining use of the senior centre; an increased age was associated with increased use. Single women used the senior centres more than married women, whereas single men used the centres less than married men. No significant socio-demographic differences were found, and the association with age could not be explained by any socio-demographic, psychosocial or health variables (5).

For the second cross-sectional study table 2 illustrates the distribution of demographic characteristics, diagnoses, physical impairments, psychological distress and social support by gender and for the total sample.

The percentage of physical impairments in each of the indices was $29-41 \%$. Hearing impairment was the most prevalent at $41 \%$, whereas musculoskeletal ailments proved to be the most common diagnosis at $34 \%$. For women, we reported three times as high a prevalence of psychological distress than for men. The sample reflects well-known gender differences in psychological distress, although psychological distress increased with age for both women and men, and its prevalence was $8.4 \%$. Poor social support (score 3-8) was most frequent in women, with a total of $28 \%$.

The associations between HSCL-10 cut-off $\geq 1.85$ and social support, demographic characteristics, diagnoses and physical impairments adjusted for gender and age, are presented in Models 1-4, Table 3. For a detailed presentation of the results of table 3 please see Bøen, 2012 (36).

The main finding of the second cross-sectional study was that a significant and consistent association was found between social support and psychological distress regardless of the variables adjusted for (direct effect): "Number of close friends", OR 0.61 ; 95\%CI (0.47-0.80); "Concern and interest", OR 0.68; 95\% CI (0.55-0.84).

After an adjustment for social support, hearing lost its position as a significant independent predictor for psychological distress: OR 1.59** 95\% CI (1.14-2.21) in model 1 to OR 0.79 ; 95\% CI (0.96-1.94) in model 2, (mediator effect). The rest of the physical impairments still demonstrated a strong significant association with psychological distress, although the ORs were reduced in comparison to model 1 . The associations between somatic diagnoses and psychological distress were more or less eliminated. Income also maintained its position as an independent determinant for psychological distress when adjusted for all variables.

For the RCT study we hypothesized that the group programme could cause a lower score on the BDI scale and higher scores on the social support scale, life satisfaction and health variables for the participants of the programme than for the controls. The scores on the outcome variables at baseline and the 12-month followup, as well as the difference scores for the intervention 
Table 2. Distribution of socio-demographics, diagnoses, physical impairments, social support and psychological distress by gender.

\begin{tabular}{|c|c|c|c|}
\hline & $\begin{array}{c}\text { Women } \\
\mathrm{n}=1,429 \\
\mathrm{n}(\%)\end{array}$ & $\begin{array}{c}\text { Men } \\
\mathrm{n}=958 \\
\mathrm{n}(\%)\end{array}$ & $\begin{array}{c}\text { Total } \\
\mathrm{n}=2,387 \\
\mathrm{n}(\%)\end{array}$ \\
\hline \multicolumn{4}{|l|}{ Socio-demographics } \\
\hline \multicolumn{4}{|l|}{ Age group } \\
\hline $65-69$ & $268(19)$ & $187(20)$ & $455(19)$ \\
\hline $70-79$ & $667(46)$ & $459(48)$ & $1126(47)$ \\
\hline $80+$ & $501(35)$ & $312(33)$ & $813(34)$ \\
\hline \multicolumn{4}{|l|}{ Education } \\
\hline Primary, 9yrs & $800(56)$ & $373(39)$ & $1173(50)$ \\
\hline Secondary, $12 \mathrm{yrs}$ & $234(17)$ & $122(13)$ & $356(15)$ \\
\hline College/Univ $>12 \mathrm{yrs}$ & $388(27)$ & $454(48)$ & $842(36)$ \\
\hline \multicolumn{4}{|l|}{ Income in thousands (NOK) } \\
\hline 150 & $591(45)$ & $90(10)$ & $681(30)$ \\
\hline $150-200^{\prime}$ & $273(21)$ & $167(18)$ & $440(20)$ \\
\hline 200-300' & $293(22)$ & $241(26)$ & $534(24)$ \\
\hline 300 & $172(13)$ & $434(47)$ & $606(27)$ \\
\hline \multicolumn{4}{|l|}{ Marital status } \\
\hline Married/cohabiting & $633(45)$ & $742(80)$ & $1375(58)$ \\
\hline Single & $791(56)$ & $211(22)$ & $1002(42)$ \\
\hline \multicolumn{4}{|l|}{ District of town } \\
\hline Ullern & $719(50)$ & $515(54)$ & $1234(52)$ \\
\hline Østensjø & $710(50)$ & $443(46)$ & $1153(48)$ \\
\hline \multicolumn{4}{|l|}{ Diagnoses (dicotom) } \\
\hline Diabetes & $87(6)$ & $94(10)$ & $181(8)$ \\
\hline Chronic lung disease & $96(7)$ & $44(5)$ & $140(6)$ \\
\hline Osteoporosis & $260(18)$ & $22(2)$ & $282(12)$ \\
\hline Musculoskeletal ailment & $607(42)$ & $216(23)$ & $823(34)$ \\
\hline Cardiac infarction & $80(6)$ & $126(13)$ & $206(9)$ \\
\hline Angina & $99(7)$ & $104(11)$ & $203(9)$ \\
\hline Stroke & $118(8)$ & $99(10)$ & $217(9)$ \\
\hline Cancer & $216(15)$ & $125(13)$ & $341(14)$ \\
\hline \multicolumn{4}{|c|}{ Physical impairment (dicotom) } \\
\hline Balance & $617(44)$ & $322(34)$ & $939(40)$ \\
\hline Vision & $450(32)$ & $228(24)$ & $678(29)$ \\
\hline Hearing & $513(36)$ & $435(46)$ & $948(41)$ \\
\hline Urine leak & $444(32)$ & $334(35)$ & $778(33)$ \\
\hline Memory & $505(36)$ & $362(38)$ & $867(37)$ \\
\hline \multicolumn{4}{|l|}{ Social support ( 3 items) } \\
\hline \multicolumn{4}{|c|}{ Number of friends to count on } \\
\hline None & $51(4)$ & $17(2)$ & $68(3)$ \\
\hline $1-2$ & $431(30)$ & $245(26)$ & $676(29)$ \\
\hline $3-5$ & $557(39)$ & $403(42)$ & $960(41)$ \\
\hline $5+$ & $381(27)$ & $288(30)$ & $669(28)$ \\
\hline \multicolumn{4}{|l|}{ Concern from others } \\
\hline A lot & $396(30)$ & $261(29)$ & $657(29)$ \\
\hline Some & $583(44)$ & $423(46)$ & $1006(45)$ \\
\hline Uncertain & $262(20)$ & $164(18)$ & $426(19)$ \\
\hline Little & $59(5)$ & $45(5)$ & $104(5)$ \\
\hline None & $23(2)$ & $20(2)$ & $43(2)$ \\
\hline \multicolumn{4}{|l|}{ Practical help } \\
\hline Very easy & $118(9)$ & $93(10)$ & $211(9)$ \\
\hline Easy & $248(18)$ & $192(21)$ & $440(19)$ \\
\hline Possible & $551(40)$ & $404(44)$ & $955(42)$ \\
\hline Difficult & $271(20)$ & $161(18)$ & $432(19)$ \\
\hline Very difficult & $190(14)$ & $70(8)$ & $260(11)$ \\
\hline \multicolumn{4}{|l|}{ Social support (sum score) } \\
\hline Poor support & $357(28)$ & $193(22)$ & $550(25)$ \\
\hline Moderate support & $656(51)$ & $469(53)$ & $1125(52)$ \\
\hline Strong support & $275(21)$ & $227(26)$ & $502(23)$ \\
\hline \multicolumn{4}{|l|}{ HSCL-10>1,85 } \\
\hline Total & $136(12)$ & $36(4)$ & $172(8)$ \\
\hline $65-69$ & $20(8)$ & $6(3)$ & \\
\hline $70-79$ & $56(10)$ & $16(4)$ & \\
\hline $80+$ & $60(16)$ & $14(5)$ & \\
\hline
\end{tabular}

group and the control group, are shown in Table 4.

There was an increase in social support in both groups, but greatest in the intervention group. The level of depression increased for both groups, but more so in the control than the intervention group. There was a decrease in life satisfaction, although the decrease was largest among controls. However, effect sizes were small and differences were not statistically significant. Hence, according to these results, the clinical significance is questionable. However, it should be noted that 32 participants said the intervention meant much to them and 5 participants said that it meant little.

To look for a possible 'dose-response' effect, the outcome measures were correlated with the number of times participated in the group meetings. Both with respect to BDI, social support and health, improvements increased in step with the increasing number of times that the persons participated in the group meetings, whereas this was not the case for life satisfaction. Correlations were on the order of 0.1-0.2 (not shown in table), and none of them were significant. Although not statistically significant $(\mathrm{p}<0.08)$, the results indicate that those who valued the meetings as most meaningful also experienced the most improvement in social support. Half the intervention group had made new friends, and 25 participants now availed themselves of more of the activities at the senior centres.

\section{Discussion}

Firstly the results presented in this article provide documentation on socio-demographics, psychosocial and health characteristics of senior centre users compared to non-users. Secondly the results indicate that lack of social support and somatic health problems may lead to increased psychological distress. Physical impairments in general and hearing in particular, were associated with low levels of social support, which again was associated with psychological distress.

Thirdly, according to our data, the intervention in all probability failed to meet optimistic targets, but a modest effect cannot be rejected. The latter possibility of a modest effect is supported by the positive reporting with respect to satisfaction with the intervention and a tendency toward dose-response effect from participants who stayed in the group until the study period ended.

The present study shows that social contact and support are vital for the quality of life of elders, and that of equal importance with good physical health in the prevention of depression and anxiety (5). The study also reveals that $25 \%$ of the informants experienced little contact and support and there was a relatively high percentage of physical impairments. Regarding the increasing number of older persons there is need for a more focused development of health promotion and prevention strategies of depressive conditions to prevent, reveal and treat these conditions and develop good health and social services. Both treatment and prevention of late-life depression has shown good results. An effectiveness trial proved a Coping With Depression Course to be effective for older persons with subclinical depression, as well as for those with a current major depression (37). The authors of a systematic review of prospective controlled trials, including 69 
Table 3. Associations ORs and $95 \%$ CI, between dependent variable: psychological distress (HSCL-10 $\geq 1.85$ ), socio-demographics, somatic health-problems and social support (OSS-3) $(\mathrm{n}=2,387)$.

\begin{tabular}{|c|c|c|c|c|c|}
\hline \multirow{2}{*}{$\begin{array}{l}\text { Independent } \\
\text { variables } \\
\text { Social support }\end{array}$} & $\begin{array}{l}\text { Model } 1 \\
\text { Each predictor adjusted } \\
\text { for age and gender }\end{array}$ & $\begin{array}{l}\text { Model } 2 \mathrm{a} \text { and } \mathrm{b} \\
\text { Adjusted for age, gender } \\
\text { and social support }\end{array}$ & $\begin{array}{l}\text { Adjusted for age, gender, } \\
\text { social support and socio- } \\
\text { demographics }\end{array}$ & \multicolumn{2}{|c|}{$\begin{array}{l}\text { Model } 4 \\
\text { Adjusted for all } \\
\text { variables }\end{array}$} \\
\hline & & & & & \\
\hline Number of close friends & $0,44 * * *(0,36-0,54)$ & & & $0,61 * *$ & $(0,47-0,80)$ \\
\hline Concern and interest & $0,52 * * *(0,44-0,61)$ & & & $0,68 * *$ & $(0,55-0,84)$ \\
\hline Practical help from neighbours & $0,74 * * *(0,64-0,86)$ & & & 1,13 & $(0,93-1,37)$ \\
\hline \multicolumn{6}{|l|}{ Demography } \\
\hline \multicolumn{6}{|l|}{ Education } \\
\hline Primary, 9yrs (ref) & 1,00 & & & 1,00 & \\
\hline Secondary, $12 \mathrm{yrs}$ & $0,55^{*} \quad(0,33-0,90)$ & & & 0,75 & $(0,39-1,43)$ \\
\hline College/Univ $>12 \mathrm{yrs}$ & $0,60 * * \quad(0,41-0,88)$ & & & 1,04 & $(0,61-1,75)$ \\
\hline \multicolumn{6}{|l|}{ Income in thousands (NOK) } \\
\hline $150^{\prime}$ (ref) & 1,00 & & & 1,00 & \\
\hline $150-200$ & $0,51 * * \quad(0,33-0,81)$ & & & $\mathbf{0 , 5 3 *}$ & $(0,31-0,91)$ \\
\hline $200-300$ & $0,42 * * *(0,27-0,65)$ & & & $\mathbf{0 , 5 4 *}$ & $(0,31-0,94)$ \\
\hline $300+$ & $0,21 * * *(0,12-0,39)$ & & & $\mathbf{0 , 3 1 *}$ & $(0,19-0,83)$ \\
\hline \multicolumn{6}{|l|}{ Marital status } \\
\hline Married/cohabiting (ref) & 1,00 & & & 1,00 & \\
\hline Single & $1,48 * \quad(1,05-2,08)$ & & & 1,37 & $(0,90-2,08)$ \\
\hline \multicolumn{6}{|l|}{ District of town } \\
\hline Ullern (ref) & 1,00 & & & 1,00 & \\
\hline Østensjø & $1,71 * * \quad(1,24-2,36)$ & & & 1,10 & $(0,71-1,72)$ \\
\hline \multicolumn{6}{|l|}{$\begin{array}{l}\text { Somatic health problems, } 2 a, b \text { and } \\
\text { 3a,b }\end{array}$} \\
\hline \multicolumn{6}{|l|}{ Diagnoses $2 \mathrm{a}$ and $3 \mathrm{a}$} \\
\hline Diabetes & $(0,83-2,53)$ & $(0,76-2,47)$ & $(0,73-2,58)$ & 0,86 & $(0,41-1,81)$ \\
\hline Chronic lung disease & $2,04 * * \quad(1,21-3,46)$ & $(0,95-2,98)$ & $(0,85-2,81)$ & 1,25 & $(0,67-2,35)$ \\
\hline Osteoporosis & $2,52 * * *(1,71-3,71)$ & $2,28 * * *(1,51-3,46)$ & $2,38 * * *(1,54-3,68)$ & 1,59 & $(0,98-2,56)$ \\
\hline Musculoskeletal ailments & $2,19 * * *(1,59-3,03)$ & $1,90 * * *(1,35-2,69)$ & $1,77 * * \quad(1,23-2,53)$ & $1,50 *$ & $(1,01-2,22)$ \\
\hline Cardiac infarction & $2,09 * * \quad(1,29-3,37)$ & $1,85^{*} \quad(1,10-3,10)$ & $(1,04-3,05)$ & 1,70 & $(0,94-3,08)$ \\
\hline Angina & $2,10 * * \quad(1,32-3,34)$ & $1,67 * \quad(1,01-2,77)$ & $(1,02-2,90)$ & 1,25 & $(0,69-2,26)$ \\
\hline Stroke & $2,09 * * \quad(1,34-3,28)$ & $1,75 * \quad(1,07-2,85)$ & $(0,86-2,40)$ & 0,87 & $(0,50-1,51)$ \\
\hline Cancer & $1,01 \quad(0,66-1,55)$ & $0,85 \quad(0,54-1,36)$ & $(0,48-1,29)$ & 0,87 & $(0,51-1,47)$ \\
\hline Diagnoses, sum & $1,70 * * *(1,48-1,96)$ & $1,53 * * *(1,32-1,78)$ & $1.50 * * *(1,27-1,77)$ & $1,29 * *$ & $(1,08-1,54)$ \\
\hline \multicolumn{6}{|l|}{ Physical impairment, $2 b$ and $3 b$} \\
\hline Balance & $6,58 * * *(4,41-9,83)$ & $5,16 * * *(3,41-7,81)$ & $5,53 * * *(2,97-6,91)$ & $2,66 * *$ & $(1,67-4,22)$ \\
\hline Vision & $4,06 * * *(2,92-5,65)$ & $3,31 * * *(2,33-4,70)$ & $3,07 * * *(2,12-4,44)$ & $2,21 * *$ & $(1,48-3,31)$ \\
\hline Hearing & $1,59 * * \quad(1,14-2,21)$ & $0,79 \quad(0,96-1,94)$ & $1,30 \quad(0,90-1,87)$ & 0,87 & $(0,58-1,30)$ \\
\hline Urine leak & $3,42 * * *(2,45-4,78)$ & $3,02 * * *(2,11-4,31)$ & $3,13 * * *(2,16-4,54)$ & $2,02 * *$ & $(1,43-3,20)$ \\
\hline Memory & $3,63 * * *(2,57-5,11)$ & $3,32 * * *(2,31-4,78)$ & $3,06 * * *(2,10-4,47)$ & $1,99 * *$ & $(1,31-3,00)$ \\
\hline Impairments, sum & $2,10 * * *(1,84-2,38)$ & $1,98 * * *(1,72-2,27)$ & $1,90 * * *(1,65-2,20)$ & $1,84 * *$ & $(1,59-2,13)$ \\
\hline
\end{tabular}

Model 1: Separate logistic regression analyses with each predictor, one by one, controlled for age and gender.

Model $2 \boldsymbol{a}$ and $\boldsymbol{b}$ : Logistic regression analyses controlled for age, gender and social support with separate analyses for diagnoses and physical impairments. In model $2 \mathrm{a}$ we have treated all diagnoses as one group without physical impairments. In model $2 \mathrm{~b}$ we have treated all physical impairments as one group without diagnoses.

Model $3 \boldsymbol{a}$ and $\boldsymbol{b}$ : Logistic regression analyses controlled for age, gender, social support and other socio-demographic factors with separate analyses for diagnoses and physical impairments. In model 3 a we have treated all diagnoses as one group without physical impairments. In model $3 \mathrm{~b}$ we have treated all physical impairment as one group with diagnoses.

Model 4: Logistic regression analyses controlled for all variables introduced simultaneously; age, gender, social support, socio-demographic factors, diagnoses and physical impairments.

${ }^{*} p<0.05 ; * *<<0.01 ; * * p<0.001$

studies, recommend that meaningful social activities, tailored to the older individuals abilities and preferences should be considered in the promotion of mental health and prevention of depression among older people (38).

However, finding studies reporting effect of service offered in senior centres targeting depression, health and satisfaction with life has been difficult. Apparently few systematic studies of effect with these outcomes are done (39). The studies of Leveille (40), Wallace (41) and Phelan (42), are effect studies and are all conducted in senior centres located in the same district in Washington, with the aims of evaluating the effect of disability-prevention programs where physical activity among frail older adults was the important outcome. The outcomes of depression and social functioning were connected to the programs of physical activity rather than to effects of social support. Apart from improved physical activity the results of the three American studies presented, showed fewer depressive symptoms, reduction of the number of depressed and less use of psychoactive medications. With respect to 
Table 4. Descriptive mean score, standard deviations on the scales of life satisfaction, health, social support and Beck Depression Inventory at baseline and after 12 months, $\mathrm{n}$ total $=92 *$

\begin{tabular}{|c|c|c|c|c|c|c|c|c|c|c|c|}
\hline \multirow{2}{*}{$\begin{array}{l}\text { Instruments and } \\
\text { scoring range }\end{array}$} & \multicolumn{4}{|c|}{ Baseline } & \multicolumn{3}{|c|}{12 months follow-up } & \multicolumn{3}{|c|}{$\begin{array}{l}\text { Differences Baseline- } \\
12 \text { months }\end{array}$} & \multirow{2}{*}{$\begin{array}{l}\begin{array}{l}\text { Effect } \\
\text { size }\end{array} \\
\text { Cohen's d }\end{array}$} \\
\hline & Groups & $n$ & Mean score & S.D. & $n$ & Mean score & S.D. & $n \mathrm{I}$ & Mean change & S.D. & \\
\hline Life satisfaction & Intervention & 37 & 3.65 & 0.82 & 37 & 3.59 & 0.76 & 37 & -0.06 & 0.78 & 0.22 \\
\hline $1-5$ & Control & 55 & 3.84 & 0.71 & 54 & 3.61 & 0.79 & 54 & -0.22 & 0.74 & \\
\hline Health & Intervention & 36 & 2.44 & 0.65 & 37 & 2.24 & 0.72 & 36 & -0.20 & 0.74 & 0.07 \\
\hline $1-4$ & Control & 55 & 2.55 & 0.60 & 55 & 2.40 & 0.63 & 55 & -0.15 & 0.52 & \\
\hline Social support & Intervention & 37 & 9.32 & 2.02 & 37 & 9.97 & 2.05 & 37 & 0.65 & 1.46 & 0.12 \\
\hline $3-14$ & Control & 53 & 9.21 & 2.00 & 54 & 9.69 & 2.09 & 52 & 0.48 & 1.72 & \\
\hline BDI & Intervention & 36 & 10.14 & 6.63 & 37 & 10.70 & 5.95 & 36 & 0.56 & 5.45 & 0.03 \\
\hline & Control & 53 & 8.70 & 4.85 & 55 & 9.44 & 4.19 & 53 & 0.74 & 4.72 & \\
\hline
\end{tabular}

* $\mathrm{n}$ differs, both in intervention group and in control group because not all the participants answered all the questions at baseline and 12 months follow-up.

social functioning two of the three studies showed that the participants more than tripled their rates of reported participation in senior centres and improved social functioning. For the third study the proportion of social contact did not materially change.

The modest effect observed on BDI was somewhat surprising. The high percentage of dropouts during the enrolment process, which may have led to selection bias, and the low number of participants that caused low statistical power, are discussed in Bøen et al. 2012 (43). Nevertheless, we may draw some conclusions from the data. Since all $95 \%$ confidence intervals of effect estimates clearly overlap with zero, it is impossible to reject the null hypothesis that the intervention did not have any effect. That does not in itself mean that the intervention cannot have been effective, as there may have been positive effects that did not reach a statistically significant level due to the small sample size. A possible explanation for the non-significant result of the BDI could be that the level of depression in the sample at baseline was too low for a substantial effect to be expected from the intervention. But this explanation is not supported by subgroups analyses of the data. There we found, in contrast to our expectations, that the program seemed less effective for those who were depressed at baseline than the rest, especially that the course of depression seemed more favorable among the controls than the group participants. An alternative explanation is therefore that an intervention of this type does not so much serve to improve the condition of those who already have manifest depression, but rather to avert development of more severe depression in those who have mild symptoms.

Our expectations were based on results from other Norwegian psychosocial intervention research among elders were the intervention groups obtained significantly better mental health, improved social network and quality of life than the control groups (44).

\section{Conclusions}

High age and specific health problems were associated with increased use of senior centres. Single women used the senior centres more than married women, whereas single men used the senior centres less than married men. A lack of social support and somatic health problems increased psychological distress. Physical impairments in general, and hearing in particular, were associated with low levels of social support, which again was associated with psychological distress. Late-life depression is a public health problem because the prevalence of physical impairments is high and lack of social support is quite common, thus possibly leading to increased psychological distress. There were no significant effects on depression of the group programme, although the programme may have delayed a general age-dependent increase in depression, and indicate a moderately improved social support and quality of life. A further evaluation of this specific service offered, including both users and non-users is needed, to gain knowledge about how senior centres may prevent social isolation and depression.

\section{REFERENCES}

1. Bøen H. Social support, mental health and effectiveness of a senior centre programme for elders living at home: cross-sectional studies and a randomized controlled trial. Oslo: Unipub, 2012.

2. Sommerfeldt E, Bevefelt E. Eldresentre i utvikling. Oslo: Norsk Gerontologisk Institutt, 1993.

3. Daatland SO, Guntvedt OH, Slagsvold B. Eldresenteret nå og framover. Oslo: NOVA Rapport 17/00, 2001.

4. Pettersen AM, Laake K. Hvem bruker eldresenteret? hva er viktig for å ta senteret $i$ bruk? Oslo: Nasjonalforeningens forskergruppe i geriatri Universitetsseksjonen, Geriatrisk avdeling, Ullevål sykehus, 2000. 
5. Bøen H, Dalgard OS, Johansen R, Nord E. Socio-demographic, psychosocial and health characteristics of Norwegian senior centre users: A cross-sectional study. Scand J Public Health 2010; 38: 508-17.

6. Blazer DG. Depression in late life: review and commentary. Focus 2009; 7 (1): 118.

7. Stordal E, Bjelland I, Dahl AA, Mykletun A. Anxiety and depression in individuals with somatic health problems. The Nord-Trøndelag Health Study (HUNT). Scand J Prim Health Care 2003; 21 (3): 136-41.

8. Prince MJ, Harwood RH, Thomas A, Mann AH. A prospective population-based cohort study of the effects of disablement and social milieu on the onset and maintenance of late-life depression. The Gospel Oak Project VII. Psychol Med 1998; 28 (2): 337-50.

9. Üstün TB, Ayuso-Mateos JL, Chatterji S, Mathers C, Murray CJL. Global burden of depressive disorders in the year 2000. Br J Psychiatry 2004; 184 (5): 386.

10. Smit F, Ederveen A, Cuijpers P, Deeg D, Beekman A. Opportunities for cost-effective prevention of late-life depression: an epidemiological approach. Arch Gen Psychiatry 2006; 63 (3): 290-6.

11. Stordal E, Bjartveit KM, Dahl NH, Kruger Ø, Mykletun A, Dahl AA. Depression in relation to age and gender in the general population: the Nord-Trøndelag Health Study (HUNT). Acta Psychiatr Scand 2001; 104 (3): 210-6.

12. Langballe EM, Evensen M. Eldre i Norge: Forekomst av psykiske plager og lidelser. Oslo: Nasjonalt folkehelseinstitutt, 2011, rapport nr. 3/1/2011.

13. Prince MJ, Harwood RH, Blizard RA, Thomas A, Mann AH. Social support deficits, loneliness and life events as risk factors for depression in old age. The Gospel Oak Project VI. Psychol Med 1997; 27 (2): 323-32.

14. Fiske A, Wetherell JL, Gatz M. Depression in older adults. Annu Rev Clin Psychol 2009; 5: 363-89.

15. Perissinotto CM, Stijacic Cenzer I, Covinsky KE. Loneliness in older persons: a predictor of functional decline and death. Arch Intern Med 2012; 172 (14): 1078-83.

16. Berkman L, Glass TA. Social integration, social networks, social support, and health. In: Berkman L, Kawachi I, editors. Social Epidemiology. New York: Oxford Univerity Press, 2000: 137-73.

17. Cohen S, Wills TA. Stress, social support, and the buffering hypothesis. Psychol Bull 1985; 98 (2): 310.

18. Golden J, Conroy RM, Bruce I, Denihan A, Greene E, Kirby M, et al. Loneliness, social support networks, mood and wellbeing in community-dwelling elderly. Int J Geriatric Psychiatry 2009; 24 (7): 694-700.

19. Heikkinen RL, Kauppinen M. Depressive symptoms in late life: a 10-year follow-up. Arch Gerontol Geriatr 2004; 38 (3): 239-50.

20. Moak ZB, Agrawal A. The association between perceived interpersonal social support and physical and mental health: results from the National Epidemiological Survey on Alcohol and Related Conditions. J Public Health 2010; 32: 191-201.

21. Wittchen HU, Jacobi F. Size and burden of mental disorders in Europe - a critical review and appraisal of 27 studies. Eur Neuropsychopharmacol 2005; 15 (4): 357-76.

22. Harris T, Cook DG, Victor C, DeWilde S, Beighton C. Onset and persistence of depression in older peopleresults from a 2-year community follow-up study. Age Ageing 2006; 35 (1): 25-32.

23. Thorsen K. Levekår, ressurser og bruk av eldresenter. Oslo: Norsk Gerontologisk Institutt, 1983.

24. Derogatis LR, Lipman RS, Rickels KEA. The Hopkins Symtom Checklist (HSCL): A self-report symptom inventory. Behav Sci 1974; 19: 1-15.

25. Strand BH, Dalgard OS, Tambs K, Rognerud M. Measuring the mental health status of the Norwegian population: a comparison of the instruments SCL-25, SCL-10, SCL-5 and MHI-5 (SF-36). Nord J Psychiatry 2003; 57 (2): 113-8.

26. Müller JM, Postert C, Beyer T, Furniss T, Achtergarde S. Comparison of eleven short versions of the Symptom Checklist 90-Revised (SCL-90-R) for use in the assessment of general psychopathology. J Psychopathol Behav Assess 2010; 32: 246-54.

27. Dalgard OS, Dowrick C, Lehtinen V, Vazquez-Barquero JL, Casey P, Wilkinson G, et al. Negative life events, social support and gender difference in depression: a multinational community survey with data from the ODIN study. Soc Psychiatry Psychiatr Epidemiol 2006; 41 (6): 444-51.

28. European Union Public Health Information System, Dalgard OS. Social support: occurance, 2009. Available from: http://www.euphix.org/object_document/o5480n27411.html.

29. Korkeila J, Lehtinen V, Bijl R, Dalgard OS, Kovess V, Morgan A, et al. Establishing a set of mental health indicators for Europe. Scand J Public Health 2003; 31 (6): 451-9.

30. WHO Regional Office for Europe. EUROHIS: Developing Common Instruments for Health Surveys. Copenhagen: WHO Regional Office for Europe, IOS press, 2003.

31. Engstad T. Geriatri. In: Ørn S, Mjell J, Bach-Gansmo E, editors. Sykdom og behandling. Oslo: Gyldendal akademisk, 2011.

32. Beck AT, Ward CH, Mendelson ML, Mock JE, Erbaugh JK. An inventory for measuring depression. Arch Gen Psychiatry 1961; 4 (6): 561. 
33. Beck Robert A, Aaron T. Psychometric properties of the Beck Depression Inventory: Twenty-five years of evaluation. Clin Psychol Rev 1988; 8 (1): 77-100.

34. Burns A, Lawlor B, Craig S. Assessment scales in old age psychiatry. Aust N Z J Psychiatry $2000 ; 34$ (5): 888-9.

35. Richter P, Werner J, Heerlein A, Kraus A, Sauer H. On the validity of the Beck Depression Inventory. Psychopathology 2000; 31 (3): 160-8.

36. Bøen H, Dalgard OS, Bjertness E. The importance of social support in the associations between psychological distress and somatic health problems and socio-economic factors among older adults living at home: a cross sectional study. BMC Geriatr 2012; 12: 27.

37. Haringsma R, Engels GI, Cuijpers P, Spinhoven P. Effectiveness of the Coping With Depression (CWD) course for older adults provided by the community-based mental health care system in the Netherlands: a randomized controlled field trial. Int Psychogeriatrics 2005; 18 (2): 307-25.

38. Forsman AK, Schierenbeck I, Wahlbeck K. Psychosocial interventions for the prevention of depression in older adults: systematic review and meta-analysis. J Aging Health 2011; 23 (3): 387-416.

39. Håvelsrud K, Dahm KT, Reinar LM, Sletsjøe H. Effekten av aktivitetstilbud på eldresenter. Oslo: Nasjonalt kunnskapssenter for helsetjenesten, 2011, Rapport nr. 07-2011. Available from: http://www. kunnskapssenteret.no/Publikasjoner/Effekten+av+aktivitetstilbud+p\%C3\%A5+eldresenter.12212.cms.

40. Leveille SG, Wagner EH, Davis C, Grothaus L, Wallace J, LoGerfo M, et al. Preventing disability and managing chronic illness in frail older adults: A randomized trial of a community-based partnership with primary care. J Am Geriatr Soc 1998; 46 (10): 1191.

41. Wallace JI, Buchner DM, Grothaus L, Leveille S, Tyll L, LaCroix AZ, et al. Implementation and effectiveness of a community-based health promotion program for older adults. J Gerontol [A] 1998; 53 (4): M301.

42. Phelan EA, Williams B, Leveille S, Snyder S, Wagner EH, LoGerfo JP. Outcomes of a community-based dissemination of the Health Enhancement Program. J Am Geriatr Soc 2002; 50 (9): 1519-24.

43. Bøen H, Dalgard OS, Johansen R, Nord E. A randomized controlled trial of a senior centre group programme for increasing social support and preventing depression in elderly people living at home in Norway. $B M C$ Geriatr 2012; 12 (1): 20.

44. Dalgard OS. A randomized controlled trial of a psychoeducational group program for unipolar depression in adults in Norway (NCT00319540). Clin Pract Epidemol Ment Health 2006; 2: 15. 